\title{
Erratum to: Spinopelvic parameter changes and low back pain improvement due to femoral neck anteversion in patients with severe unilateral primary hip osteoarthritis undergoing total hip replacement
}

\author{
Andrea Piazzolla $^{1}$ (D) Giuseppe Solarino $^{1} \cdot$ Davide Bizzoca $^{1} \cdot$ Viola Montemurro $^{1}$.

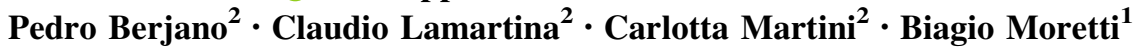

Published online: 28 April 2017

(C) Springer-Verlag Berlin Heidelberg 2017

\section{Erratum to: Eur Spine J}

DOI 10.1007/s00586-017-5033-7

Unfortunately, an author name, Carlotta Martini, was missed out in the author group of this original version. The complete corrected author group is given below.
Andrea Piazzolla ${ }^{1}$
Giuseppe Solarino $^{1}$
Davide Bizzoca $^{1}$
Viola Montemurro ${ }^{1}$
Pedro Berjano ${ }^{2}$
Claudio Lamartina ${ }^{2}$
Carlotta Martini ${ }^{2}$
Biagio Moretti ${ }^{1}$

The online version of the original article can be found under doi:10.1007/s00586-017-5033-7.

Andrea Piazzolla

dott.piazzolla@gmail.com

1 School of Medicine, University of Bari Aldo Moro, AOU

Consorziale Policlinico, Department of Basic Medical

Sciences, Neuroscience and Sense Organs, Orthopaedic,

Trauma and Spine Unit, Piazza Giulio Cesare 11, 70100 Bari,

Italy

2 GSpine4, IRCCS Istituto Ortopedico Galeazzi, Milan, Italy 